\title{
Influence of Early Life Stress on Alcohol and Crack Dependents
}

\author{
Elton Brás Camargo Júnior 1,2 (), Maria Neyrian de Fátima Fernandes ${ }^{3 *}{ }^{\circledR}$, \\ Larissa Bessani Hidalgo Gimenez ${ }^{1}\left(\mathbb{C}\right.$, Jaqueline Rodrigues Stefanini ${ }^{4}{ }^{(0)}$, \\ Ana Carolina Guidorizzi Zanetti ${ }^{1}$ (D), Edilaine Cristina da Silva Gherardi-Donato ${ }^{1}$ (i)
}

\footnotetext{
${ }^{1}$ Department of Psychiatric Nursing and Human Sciences, College of Nursing, University of São Paulo, Ribeirão Preto, Brazil ${ }^{2}$ Department of Nursing, University of Rio Verde, Rio Verde, Brazil

${ }^{3}$ Department of Nursing Coordination, University Federal of Maranhão, Imperatriz, Brazil ${ }^{4}$ Department of Nursing Coordination, Faculdade Unida of Campinas (FACUNICAMPS), Gôiania, Brazil Email: eltonbrasjr@gmail.com, neyrianfernandes@gmail.com, lari_gimenez@hotmail.com, jaqueline.rstefanini@usp.br, carolzan@eerp.usp.br, *nane@eerp.usp.br
}

How to cite this paper: Júnior, E.B.C., de Fátima Fernandes, M.N., Gimenez, L.B.H., Stefanini, J.R., Zanetti, A.C.G. and da Silva Gherardi-Donato, E.C. (2020) Influence of Early Life Stress on Alcohol and Crack Dependents. Open Journal of Nursing, 10, 490-512.

https://doi.org/10.4236/ojn.2020.105034

Received: March 30, 2020

Accepted: May 6, 2020

Published: May 9, 2020

Copyright () 2020 by author(s) and Scientific Research Publishing Inc. This work is licensed under the Creative Commons Attribution International License (CC BY 4.0).

http://creativecommons.org/licenses/by/4.0/

\section{(c) (i) Open Access}

\begin{abstract}
Background: Early life stress is a significant public health problem associated with increased rates of psychiatric disorders, especially those related to drug abuse. Objective: To identify the prevalence of early life stress in drug users, to compare the intensity of trauma in alcohol and crack users, and to relate the power of injury to the severity of drug dependence. Method: Cross-sectional analytical study with a sample of 105 alcohol and crack users treated by an outpatient service. The instruments for data collection were sociodemographic data questionnaire, the Mini-International Neuropsychiatric Interview, and the Severity of Dependence Scale. The categorical variables association was analyzed using the Chi-squared test, considering $\mathrm{p}<0.05$ significance. ANOVA was used to verify the variance. To assess the difference between sociographic and dependent variables, we used the Mann-Whitney and Kruskal-Wallis tests. Results: High prevalence of early stress and severity of dependence were identified, with higher rates among crack users. The early stress revealed in the Alcohol group high rates of emotional (88.7\%) and physical (94.3\%) neglect and in the Crack group significant frequency of physical (61.5\%) emotional abuse (51.9\%), sexual (46.2\%), and emotional $(78.8 \%)$ and physical (90.4\%) neglect. Crack users are 2.6 times more likely to have been emotionally abused, and 2.1 times more likely to have been sexually abused during childhood when compared to the alcohol group. Conclusion: Early stress was prevalent with significant intensity in drug users, and evaluation of this problem is essential for a better understanding of these disorders.
\end{abstract}




\section{Keywords}

Childhood Trauma, Adverse Childhood Experiences, Child Abuse, Early Life Stress, Substance Abuse, Crack, Alcohol

\section{Introduction}

The abusive use of psychoactive substances is considered a problematic factor of social order when observed self-destructive behaviors are consequently harmful to the person and its social environment. Approximately 35 million people worldwide have drug use disorders, an estimate that characterizes the situation as a significant public health problem [1].

For a better demonstration of the problem, it published data from a nationwide survey conducted in Brazil, in which crack has a significant prevalence among illicit drugs, reaching 1.4 million people aged 12 to 65 years who have used the drug before. The same report presents worrying data regarding alcohol consumption patterns, in which about 2.3 million people met the criteria for alcohol dependence in Brazil [2].

Alcohol is the most widely used psychoactive substance in the national context, and the use of crack cocaine, a smoked form of cocaine, has become popular because of its affordability and low price. The consumption of these substances, especially crack, has gained exponential importance in recent years due to the consequences of dependence on the individuals [2] [3]. In this context, due to the public health burden related to psychoactive substance abuse and the associated morbimortality consequences, studies are needed to identify the contributing factors for the development of psychoactive substance use disorders.

Chemical dependence is a complex problem involving several risk factors that determine their degree of consumption. Studies indicate that individuals exposed to early stress during childhood have a high risk of harmful behaviors, the development of noncommunicable diseases and the abuse of drugs in adulthood [4] [5]. Early life stress is an initial tension that stems from a variety of traumatic experiences that occur in childhood and highlight that child maltreatment is a multifaceted phenomenon [6]. The main traumatic experiences found in the literature are physical, sexual, and emotional abuse, and physical and emotional neglect [7].

Early stress is a significant public health problem associated with increased rates of psychiatric disorders, especially those related to drug abuse [8] [9] [10] [11]. Results from studies find that the high prevalence of child abuse and neglect, in which the estimated experience of at least one early childhood stress affects one in four adults globally. It makes the problems of child maltreatment even more worrisome [12] [13].

Regarding the Brazilian context, a meta-analysis published in 2016 found that the country has one of the highest estimates of child maltreatment in the world 
[14]. In addition to this problem, the Brazilian budget for the prevention of child maltreatment was considered inadequate compared to other contexts and countries [15].

Exposure during childhood to these traumatic experiences is associated with early consumption and dependence on alcohol and other psychoactive substances in adolescence and adulthood [16]-[21]. Individuals from vulnerable groups who experienced traumatic situations during childhood consumed more alcohol when compared to non-traumatized ones [22].

Research from a nationally representative sample in the United States found that physical, sexual and emotional abuse and physical and emotional neglects were associated with an increased risk of developing substance abuse disorders [23]. Besides that, there is a positive association between multiple exposure trauma and substance use disorder, showing a $34 \%$ increase in the development of the disease after each subsequent trauma [24]. In this interviewed group, neglect, emotional, and sexual abuse are more prevalent. Another research found a positive relationship between experiences of sexual abuse-related trauma with a higher risk of being a heavy drug user in women and child neglect responsible for the 2.30-fold increase in the risk of substance abuse [25].

Some studies have reported differences in early stress exposure in users of different types of drugs. A longitudinal study of a representative sample of adolescents carried out since the mid-1990s, identified a direct relationship between many traumas and higher consumption of marijuana and cocaine, with a $24 \%$ increase in chance to use cannabis for each injury experienced and a 30\% chance to use cocaine for each unit increase in the number of traumas [26].

Although some scientific researches have focused on identifying the difference in exposure to early stress in the different groups according to drug use, there is still a gap in the Brazilian context, primarily concerning crack and alcohol users.

In a study that analyzed four different groups (alcohol dependent, addicted to other drugs, depressive patients, and a control group without a diagnosis of mental disorder) the results identified a higher frequency and intensity of early life stress in the alcohol and other drug groups when compared to the depression and control groups [27]. However, researchers do not report the primary substance in the drug-dependent group. Recently, one of the only articles in the national context found in the databases was published that evaluated the experience of childhood maltreatment in groups with different drugs of choice. The authors found a higher intensity of early stress in alcohol users when compared to cocaine, crack, and tobacco users. However, the study did not analyze the influence of early stress on the severity of drug dependence [28].

It is worth mentioning the importance of analyzing specific groups of drug users, especially those dependent on alcohol and crack. There is little information available about the prevalence of early stress experienced by these two groups of drug users, especially in Latin America. The evaluation of these expe- 
riences denotes importance, considering that alcohol is the most consumed drug in the country. Crack has a high dependence factor, associated with high social vulnerability, besides being one of the main substances that lead users to seek outpatient treatment in public psychosocial care services in Brazil [29].

These existing studies highlight the importance of the spectrum of childhood traumatic experiences in the risk of drug abuse contributing to the increased severity of the addiction. Furthermore, they indicate the need for further studies that provide the identification of risk factors for lifelong drug use, as this is fundamental for the development of prevention strategies.

From this perspective, this research aims to identify the prevalence of early life stress in drug users, to compare the intensity of trauma in alcohol and crack users, and to relate the power of injury to the severity of drug dependence.

The present study hypothesizes that drug users, who are undergoing outpatient treatment, have a high prevalence of early life stress and that the frequency and intensity of trauma would differ according to the drug used. Furthermore, another hypothesis is that a higher power of early stress could result in differences in the severity of dependence between alcohol and crack users.

\section{Method}

A cross-sectional analytical study conducted in an outpatient health unit specializing in the treatment of addiction called the Psychosocial Care Center-Alcohol and Drugs (CAPSad) of a municipality of 235,647 inhabitants, located in the Midwest region of Brazil. The service provides coverage for an estimated population of 420,000. The sample consisted of 105 male and female drug users aged 18 years and over.

The data collection procedure followed the research protocol approved by the Ethics Committee (CAAE 49430015.0.0000.5077), in which all participants signed the informed consent document. The data collection period occurred between August 2018 and February 2019. All patients seeking outpatient care were invited to participate in the survey.

The study included patients who were on a new use of psychoactive substances (less than five days abstinence) and age 18 or older. These inclusion criteria were used due to the need to suppress bias related to abstinence time that influences the comprehension of the severity of the dependence. We excluded patients with intellectual disability, schizophrenia, disabling disorders noted by the research or reported by medical records, and poly-substance dependence.

Through simple random sampling, the individuals were divided into two groups according to the psychiatric clinical diagnosis made by outpatient psychiatrists and confirmed by the application of the Mini International Neuropsychiatric Interview (MINI) [30] performed in 240 patients by the researchers for six months. After evaluation, the final sample consisted of 105 individuals that were allocated according to the primary diagnosis in the Alcohol group $(\mathrm{n}=53)$ and Crack group $(\mathrm{n}=52)$ (Figure 1$)$. 


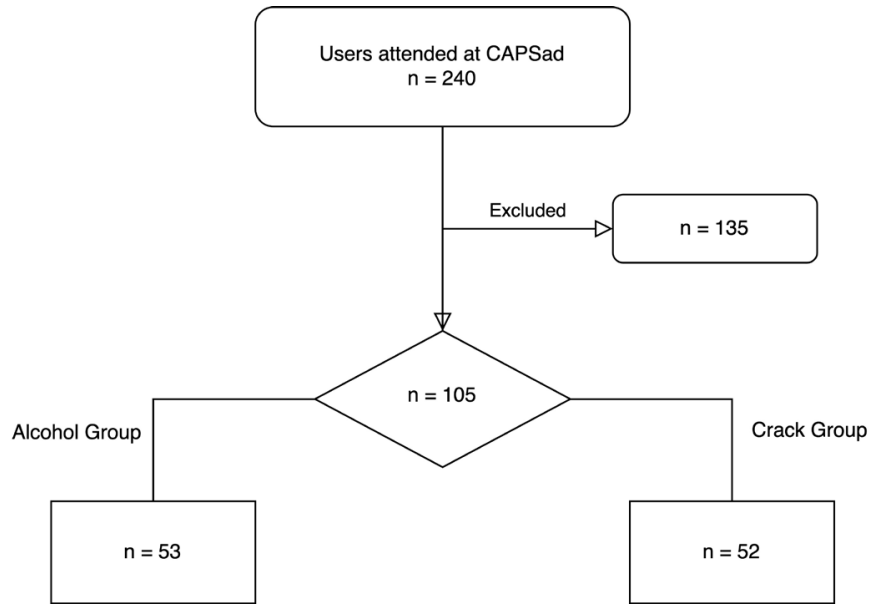

Figure 1. Flowchart of the sample selection process.

Instruments for data collection: Sociodemographic data questionnaire (gender, date of birth, race, marital status, race, education, occupational status, a specificity of the leading job) (Appendix). This questionnaire also covered questions related to the age of first use of alcohol and crack; Mini-International Neuropsychiatric Interview [30]: instrument used to define substance use disorder related to alcohol or crack use. Also, we used evaluation to diagnose psychiatric disorders listed in the exclusion criteria; Severity of Dependence Scale (SDS): developed by Gossop et al. [31] [32], aims to evaluate the level of severity of drug dependence related to psychological aspects. SDS is composed of variables that address control over drug use and the difficulty of stopping drug use. This instrument has been used in several studies in which it has demonstrated good internal reliability indexes when applied to users of heroin, cocaine, amphetamines, marijuana, alcohol, and methadone maintenance patients [33] [34] [35]. Results from the instrument come from the sum of all five questions, and the higher the score, the higher the severity level of drug dependence [31]. SDS validation study in the Brazilian version demonstrated good reliability and validity for cocaine, crack, marijuana, and alcohol users [33]; Childhood Trauma Questionnaire (CTQ): the instrument investigates the history of early stress due to abuse and neglect during childhood [6] [36]. It was translated and validated for the Brazilian context [37]. The instrument has 28 items easy to apply and has been extensively used in numerous clinical and nonclinical populations and is considered a valid and reliable tool due to the solidity of psychometric properties for the evaluation of trauma experienced during childhood [38] [39] [40]. The questionnaire assesses the five subtypes of trauma that may occur during childhood: Emotional abuse (any humiliation or verbal aggression directed from an adult to a child causing embarrassment or mental distress), Physical abuse (physical aggression caused by an adult in a child, who often leaves injuries, sequelae, and can lead to the death of the child depending on its intensity), Sexual abuse (sexual contact of children or under 18 years with an older person), Emotional neglect (caregiver's failure to meet needs emotional and psychological 
distress), Physical neglect (caregiver's failure to provide a child with food, shelter, clothing, and safety) [6]. Items are rated on a Likert scale ranging from 1 (never) to 5 (very common) [37]. According to the instrument, the application rules the severity of each trauma is classified as emotional abuse ( 5 to 8 -none to a minimum; 9 to 12 -mild to moderate; 13 to 15 -moderate to severe; above 15-severe to extreme) physical abuse (5 to 7 not minimum; 8 to 9 -mild to moderate; 10 to 12 moderate to severe; over 13 -severe to extreme) sexual abuse (5-not minimum; 6 to 7 -mild to moderate; 8 to 12 -moderate to severe; over 13-severe to extreme) emotional neglect ( 5 to 9 -not minimal; 10 to $14-$ mild to moderate; 15 to 17 -moderate to severe; over 18-severe to extreme) physical neglect ( 5 to 7 -not minimal; 8 to 9 -mild to moderate; 10 to 12 -moderate to severe; above 13-severe to extreme). After obtaining the sum of all the assertions and five scores, the classification is made through points ranging from 5 to 25 points for each subtype [6]. According to the authors of the instrument, individuals are classified as having early childhood stress if they score moderate-severe or severe-extreme for one or more subtypes.

All the patients attended CAPSad facilities were invited by the researcher to participate in the study. Then the interviewer applied the MINI and the SDS to the participants. According to the results, they were divided into Alcohol and Crack groups.

\section{Statistical Analysis}

Data analyses were exploratory and performed in IBM SPSS Statistical Program of Social Science v.20 for Windows. Study variables are described calculating average, absolute, and relative frequencies, as well as the verification of average and standard deviation for continuous variables to characterize the sample. We performed an analysis among the association of categorical variables of the Alcohol and Crack groups using the Chi-squared test $\left(\chi^{2}\right)$, considering $\mathrm{p}<0.05$ significance, using the Bonferroni post hoc correction when necessary.

The analysis of variance (ANOVA) was the statistical procedure used to look at the possible interaction of the two different groups. The Shapiro-Wilks normality test was used, confirming an asymmetric distribution to evaluate the sample distribution. To assess the difference between sociographic and dependent variables into groups, we used the nonparametric Mann-Whitney and Kruskal-Wallis tests.

Logistic regression analyses performed with adjusted ORs and CI 95\% to assess the influence of each type of abuse and neglect on the drug of use, comparing users of the Alcohol and Crack group.

\section{Results}

Our study included a total of 120 subjects, divided into two groups: Alcohol and Crack groups (Figure 1). Participants were predominantly male both in Alcohol $39(73.6 \%)$ and Crack 34 (65.4\%) groups $\left(\chi^{2}=0.83 ; \mathrm{p}=0.36\right)$. Participants' ages 
differed in the groups $\left(\chi^{2}=15.58 ; \mathrm{p}=0.001\right)$, in the Crack group users are significantly more representative in the range of $20-29$ age $(36,5 \%>9.4 \% ; \mathrm{p}=$ 0.002 ) and the percentage of crack use is significantly lower than alcohol in the age group of 50 or older $(34.0 \%>9.6 \% ; \mathrm{p}=0.004)$. Also, we found average age-difference between the two groups $(F=29.06 ; p=0.001)$, with the average age of the Alcohol group being $45.02( \pm 11.30)$, and in the Crack group, 33.85 $( \pm 9.87)$ (Table 1$)$.

Regarding skin color, the groups showed no significant differences $\left(\chi^{2}=3.76\right.$; $\mathrm{p}=0.28)$, with a predominance of black patients in the Crack (35.8\%) and Alcohol $(46.2 \%)$ groups. The marital status showed significant differences $\left(\chi^{2}=\right.$ 10.73; $\mathrm{p}=0.04)$; participants with a diagnosis of Crack-related disorder were more numerous than those among alcoholics $(65), 4 \%>39.6 \% ; \mathrm{p}=0.02$ ) (Table 1).

The groups were similar about education $\left(\chi^{2}=2.63 ; \mathrm{p}=0.45\right)$; however, it is evident the prevalence of lower education level among users who were part of the sample. The current employment situation was also similar in both groups $\left(\chi^{2}=6.03 ; p=0.11\right)$, although no significant differences were found between the groups, there was a predominance of unemployed in the evaluated users (Table 1). In the sample evaluated, the Crack group had significantly higher severity dependence scores, as measured by the Severity of Dependence Scale (SDS), (F = 7.38 ; $\mathrm{df}=1 ; \mathrm{p}=0.008)$, with an average of $10.6( \pm 2.7)$, compared to the Alcohol group with an average of $8.9( \pm 3.6)$ (Table 2$)$.

Participants from the Crack group also reported having used alcohol, although the diagnosis and treatment in the health service are related to the use of Crack. The results on the age of first use of alcohol showed a significant difference between the groups regarding the beginning of alcohol consumption $(\mathrm{F}=$ 5.14; $\mathrm{df}=1 ; \mathrm{p}=0.02$ ), and the Alcohol group started the consumption of alcohol at a later age when compared to the Crack group. Regarding the age of first use of crack, 56 individuals claim to be users or have tried the drug during their lifetime. When comparing the groups, no significant differences were found between them (Table 2).

Observing the distribution of early stress subtypes in each group we found that the Alcohol group showed high rates of emotional (88.7\%) and physical (94.3\%) neglect abuse and in the Crack group significant frequency of physical (61.5\%) emotional abuse (51.9\%), sexual (46.2\%), and emotional (78.8\%), and physical (90.4\%) neglect.

The ANOVA technique detected statistical differences between the analyzed individuals, being the Crack group with higher values when it was the average total score $( \pm \mathrm{sd})$ of the total CTQ $(\mathrm{F}=6.77 ; \mathrm{df}=1 ; \mathrm{p}=0.01)$, as well as in all subtypes of abuse, such as emotional abuse $(\mathrm{F}=6.31 ; \mathrm{df}=1 ; \mathrm{p}=0.01)$, physical abuse $(\mathrm{F}=4.82 ; \mathrm{df}=1 ; \mathrm{p}=0.03)$, sexual abuse $(\mathrm{F}=7.55 ; \mathrm{df}=1 ; \mathrm{p}=0.007)$. Regarding neglect subtypes, no statistical differences were found between the two groups (emotional: $\mathrm{p}=0.60$; physical: $\mathrm{p}=0.39$ ), as shown in Table 3 . 
Analyzing the influence of early life stress and its subtypes on the drug use found a significant influence of emotional abuse ( $\mathrm{OR}=2.64 ; 95 \% \mathrm{CI} ; 1.20-5.80)$ and sexual abuse (OR $=2.17 ; 95 \% \mathrm{CI} ; 0.97-4.88)$ in the Crack user group. That is, in the sample analyzed, crack users are 2.6 times more likely to have been emotionally abused, and 2.1 times more likely to have been sexually abused during childhood when compared to the Alcohol group. Regarding physical abuse, a tendency was found $(\mathrm{OR}=1.93 ; 95 \% \mathrm{CI} ; 0.88-4.22)$, indicating that users of the Crack group are $93 \%$ more likely to have suffered physical abuse. In analyzing the influence of neglect, no statistically significant differences were found in either emotional neglect $(\mathrm{OR}=0.47 ; 95 \% \mathrm{CI} ; 0.16-1.40)$ or physical neglect (OR $=0.56 ; 95 \%$ CI; 0.12 - 2.49) (Table 4).

Table 1. Distribution of sociodemographic characteristics according to the drug used (N = 105). Rio Verde, 2019.

\begin{tabular}{|c|c|c|c|c|}
\hline & $\begin{array}{l}\text { Alcohol } \\
53(50.5)\end{array}$ & $\begin{array}{c}\text { Crack } \\
52(49.5)\end{array}$ & $x^{2}$ & $\mathrm{p}$ \\
\hline Gender, n (\%) & & & 0.83 & 0.36 \\
\hline Male & $39(73.6)$ & $34(65.4)$ & & \\
\hline Female & $14(26.4)$ & $18(34.6)$ & & \\
\hline Age range* & & & 15.58 & 0.001 \\
\hline $20-29$ years & $5(9.4)$ & $19(36.5)$ & & \\
\hline $30-49$ years & $30(56.6)$ & $28(53.8)$ & & \\
\hline 50 years or more & $18(34.0)$ & $5(9.6)$ & & \\
\hline Age (average, sd) ${ }^{* \mathrm{~A}}$ & $45.02( \pm 11.30)$ & $33.85( \pm 9.87)$ & \multicolumn{2}{|c|}{0.001} \\
\hline Skin color & & & 3.76 & 0.28 \\
\hline Black & $19(35.8)$ & $24(46.2)$ & & \\
\hline White & $14(26.4)$ & $8(15.4)$ & & \\
\hline Brown/Mixed & $18(34.0)$ & $15(28.8)$ & & \\
\hline Others & $2(3.8)$ & $5(9.6)$ & & \\
\hline Marital status* & & & 10.73 & 0.04 \\
\hline Married & $10(18.9)$ & $6(11.5)$ & & \\
\hline Living as married & $7(13.2)$ & $7(13.5)$ & & \\
\hline Widowed & $3(5.7)$ & $0(0)$ & & \\
\hline Divorced & $10(18.9)$ & $5(9.6)$ & & \\
\hline Separated & $2(3.8)$ & $0(0)$ & & \\
\hline Single & $21(39.6)$ & $34(65.4)$ & & \\
\hline Schooling & & & 2.63 & 0.45 \\
\hline Illiterate & $10(18.9)$ & $6(11.5)$ & & \\
\hline Incomplete/complete primary & $27(50.9)$ & $33(63.5)$ & & \\
\hline Incomplete/complete secondary & $13(24.5)$ & $12(23.1)$ & & \\
\hline Incomplete/complete tertiary & $3(5.7)$ & $1(1.9)$ & & \\
\hline Current Employment & & & 6.03 & 0.11 \\
\hline Employed & $11(20.8)$ & $5(9.6)$ & & \\
\hline Unemployed & $31(58.5)$ & $37(71.2)$ & & \\
\hline Freelancing & $6(11.3)$ & $9(17.3)$ & & \\
\hline Retired & $5(9.4)$ & $1(1.9)$ & & \\
\hline
\end{tabular}


Table 2. Severity of dependence and age of first alcohol and crack use $(n=105)$. Rio Verde, 2019.

\begin{tabular}{cccc}
\hline & Alcohol & Crack & p \\
\hline SDS $^{* \mathrm{~A}}($ Alcohol $=53$; Crack $=52)$ & $8.9( \pm 3.6)$ & $10.6( \pm 2.7)$ & 0.008 \\
Age of first alcohol use ${ }^{\star \mathrm{A}}(\mathrm{n}=105)$ & $17.0( \pm 6.9)$ & $14.3( \pm 5.1)$ & 0.02 \\
Age of first crack use ${ }^{\mathrm{A}}(\mathrm{n}=56)$ & $24.0( \pm 8.0)$ & $20.8( \pm 7.8)$ & 0.29 \\
\hline
\end{tabular}

${ }^{*}=\mathrm{p}<0.05 ; \mathrm{A}=$ ANOVA.

Table 3. Intensity of early stress subtypes, according to CTQ ( $\mathrm{n}=105)$. Rio Verde, 2019.

\begin{tabular}{cccc}
\hline & $\begin{array}{c}\text { Alcohol } \\
(\mathrm{n}=53)\end{array}$ & $\begin{array}{c}\text { Crack } \\
(\mathrm{n}=52)\end{array}$ & $\mathrm{p}$ \\
\hline CTQ Total & $58.0( \pm 13.6)$ & $66.7( \pm 18.1)$ & 0.01 \\
Emotional Abuse & $11.7( \pm 5.5)$ & $14.3( \pm 5.3)$ & 0.01 \\
Physical Abuse & $9.3( \pm 5.3)$ & $11.8( \pm 6.1)$ & 0.03 \\
Sexual Abuse & $7.1( \pm 4.0)$ & $10.0( \pm 6.6)$ & 0.01 \\
Emotional Negligence & $15.7( \pm 5.6)$ & $15.1( \pm 5.3)$ & 0.60 \\
Physical Negligence & $14.6( \pm 3.5)$ & $15.3( \pm 4.3)$ & 0.39 \\
\hline
\end{tabular}

${ }^{*} \mathrm{p}<0.05$.

Table 4. Influence of early stress subtypes on alcohol and crack use $(\mathrm{n}=105)$. Rio Verde, 2019.

\begin{tabular}{cccc}
\hline & OR & $\begin{array}{c}\text { CI (95\%) } \\
\text { LI - LS }\end{array}$ & p \\
\hline Emotional Abuse* $^{*}$ & 2.64 & $1.20-5.80$ & 0.02 \\
Physical Abuse* & 1.93 & $0.88-4.22$ & 0.03 \\
Sexual Abuse & 2.17 & $0.97-4.88$ & 0.05 \\
Emotional Negligence & 0.46 & $0.12-1.40$ & 0.18 \\
Physical Negligence & 0.56 & $0.12-2.49$ & 0.45 \\
\hline
\end{tabular}

${ }^{*} \mathrm{p}<0.05$.

\section{Discussion}

The present study is one of the first in the Brazilian context to analyze the frequency, severity, and influence of early life stress from five types of childhood trauma on alcohol and crack dependence. The study results show the importance of the problem concerning early life stress and the need for attention to this situation, considering that drug use and the severity of dependence may be related to traumatic events experienced during childhood and adolescence.

Participants on the present study was selected by simple random sampling in an outpatient unit for the treatment of substance use disorders, which highlights the problem involving alcohol and crack use in Brazil. It is important to report that no individuals declined to take part in the research after being approached by the researcher. The high prevalence of alcohol dependents in the sample re- 
flects the national panorama of alcohol consumption, being the most consumed drug in the country [2]. Regarding crack use, although the national prevalence of its use has remained stable in recent years [2] [41], the abusive consumption results in severe consequences for the user. It is evidencing the harm of crack consumption by the demand of these users in seeking outpatient treatment [42].

Our baseline results show that our sample has a similar socio-demographic profile, as reported in other studies, including the majority of black, low-educated level, and unemployed men [43] [44]. Crack consumption was significantly higher when compared to alcohol in young adults with an average age of 33.85 ( \pm 9.87$)$ and a single $34(65.4)$.

The literature points out those environmental factors, such as family environment and interpersonal relationships, are influential variables in drug use, interacting mutually with other elements in a dynamic process [45] [46]. Besides, the break-in family ties may also be a consequence of drug abuse and the drug of choice, as observed through a study in which the characteristics of family functioning in crack users were more impaired when compared to alcohol users [47]. Although not demonstrating statistically significant differences between the two groups, the predominance of unemployed users reflects the problem of high social vulnerability to which these users are exposed, suggesting a trajectory of social marginalization that precedes or is a consequence of drug use [48].

Regarding the severity of drug dependence, the Crack group had significantly higher scores than the Alcohol group evaluated by the Severity of Dependence Scale instrument. Crack users tend to seek health care because they have higher rates of acute situations caused by substance use and are more likely to report other health-related problems [49]. Another foundation regarding the severity of drug dependence concerns the influence of the drug administration route. Studies have shown more severe health consequences for crack users compared to users of other drugs, such as alcohol. They suggest that this may be related to the route in which this substance is administered and the health consequences to drug users [49] [50].

Crack users have more significant social and judicial damages and other psychosocial problems when compared to users of other drugs, which contributes to the increasing severity of addiction [51] [52]. Besides, the age of onset of drug use influences substance dependence, and the findings of the present study showed that the Crack group started alcohol consumption earlier. It is noteworthy that early drug use can be postulated by the role that early stress entails in the initiation and maintenance of drug use. Thus, the early onset of substance abuse has also been related to more considerable experience of early stress [53] [54].

A research describes the association between early stress and premature age at the onset of drug use and consequently concludes that lifetime dependence is significantly higher if drug use initiates in adolescence [55]. Thus, the Crack group, having experienced higher frequencies and intensities of early stress, be- 
gan the consumption of substances younger than the Alcohol group, and premature expenditure can be justified as a way of regulating negative emotions resulting from early stress [26] [56].

The presence of early life stress in the analyzed sample indicates high rates of emotional (88.7\%) and physical (94.3\%) neglect among alcohol users; and emotional abuse (61.5\%), physical abuse (51.9\%), and emotional (78.8\%) and physical (90.4\%) neglect among crack users. Statistical analyses showed a significant difference between the two groups in trauma related to emotional $(\mathrm{p}=0.01)$ and sexual $(\mathrm{p}=0.05)$ abuse. In this context, we confirm part of our hypothesis regarding the difference in the presence of early stress subtypes in the analyzed groups.

The results of the present study corroborate the literature showing high exposure to early stress in people diagnosed with substance use disorders [28] [57] [58] [59]. In retrospective studies, the prevalence of early life stress relates to the problematic use of alcohol [60], crack [61], and injecting drugs [62].

Recent studies in Brazil have evaluated early life stress exposure among psychoactive substance users using specific samples, usually focused on gender differences. However, few compared early life stress according to the drug of choice of the user [27] [63] [64]. One study aimed to evaluate patients undergoing treatment for substance dependence reported among alcohol users showed a prevalence of neglect similar to our research, with physical neglect prevalent in $85.4 \%$ and emotional neglect in $98.9 \%$ of the sample. When compared to the crack user sample, the authors found a higher frequency of emotional abuse (91.3\%), physical abuse (69.6\%), physical neglect (84.8\%), and emotional neglect (95.7\%). However, our study sample showed a higher prevalence of sexual abuse among crack users compared with the reference study [28].

To better elucidate the prevalent relationship between early stress and substance use disorders, a systematic review and meta-analysis determined the prospective link between these two conditions through longitudinal studies [65]. The results demonstrated a high magnitude of the association between outcome and history of childhood physical and sexual abuse, with a $74 \%$ and $73 \%$ increase in the risk of illicit substance abuse, respectively, when experiencing such abuse [65].

Regarding the intensity of trauma experienced by the Alcohol and Crack groups, the total early stress score was significantly higher in crack users, as well as in the emotional abuse, physical abuse, and sexual abuse subtypes when compared to the alcohol user's group. Therefore, crack users reported experiencing more severe child trauma (except emotional neglect). The study hypothesis that there was a difference in trauma intensity in both groups was confirmed.

The findings of this study show a high intensity of early stress in our sample of Crack users when compared to the survey [66] who identified a total early stress intensity with a score of $48.8( \pm 18.1)$, emotional abuse $11.7( \pm 5.4)$ physical abuse $10.0( \pm 5.3)$, sexual abuse $7.2( \pm 4.4)$, and physical neglect $8.8( \pm 3.8)$ and emotional $11.0( \pm 5.3)$. Regarding the intensity of early stress in alcohol users, the 
results of our sample were also higher than those presented in another research [67] in the CTQ total score $44.1( \pm 17.1)$, as well as early stress subtypes such as emotional abuse $9.8( \pm 5.1)$, sexual abuse $7.6( \pm 5.6)$, physical abuse $8.8( \pm 4.3)$, emotional neglect $10.4( \pm 5.0)$ and physical neglect $7.4( \pm 3.6)$. The comparison between these results shows the severity of early stress among psychoactive substance users in the present sample.

The scientific literature indicates that early life stress may influence the severity, prognosis, and evolution of crack consumption [61] [68]. An explanatory model for this is the adaptation of the hypothalamus-pituitary-adrenal axis that occurs since early life, with the resulting cortisol secretion responsible for metabolic, immunological, cognitive, and behavioral adjustments to stress. From the moment stress becomes chronic early in life, there is an allostatic overload of the hypothalamus-pituitary-adrenal axis, which causes impairment of stress adaptation mechanisms and results in maladaptive response as the highest chance of developing dependence [50].

One research identified a significant association between early stress and the chance of developing crack addiction, in which the sample showed higher scores on early stress subtypes, citing emotional and physical abuse, as well as emotional and physical neglect [61]. The results of our study provide additional support for previous research that identified the influence of early stress severity on adverse outcomes in drug dependence [3] [69].

The higher intensity of early stress experienced among crack users leads us to consider the use of a substance with high potential dependence as an inappropriate strategy to cope with strongly negative experiences during childhood, resulting in more substantial use over time. Therefore, exposure to trauma can influence the type of addiction drug and cause a greater severity of addiction to this drug [52] [69] [70].

In the present study, the different types of abuse were significant in the sample of Crack users, showing that belonging to this group increased the chances of emotional abuse $(\mathrm{OR}=2.64 ; 95 \% \mathrm{CI} ; 1.20-5.80)$ and sexual abuse $(\mathrm{OR}=2.17$; $95 \% \mathrm{CI} ; 0.97-4.88)$, as well as a tendency towards physical abuse $(\mathrm{OR}=1.93$; $95 \%$ CI; $0.88-4.22$ ).

The effect of early life stress on drug users, especially crack users, demonstrates the social vulnerability in which drug addicts were inserted [3]. Exposure to different types of abuse may have played a prominent role in the development of drug addiction, such as crack, as well as being a potentiator to worsen addiction in adulthood. Early life stress characterized as a pathogenic relational experience and individuals exposed to abuse and neglect initiates a negative probabilistic cascade in various processes at various levels and domains of life, increasing the risk of developing the drug-related disorder [71] [72].

The early life stress increases the risk of substance use problem during adolescence in which a sequence of family-based risk factors like childhood maltreatment has been described, associated with heterogeneous developmental outcomes, including the development of less adaptive personality organizations, 
psychopathology, and substance use disorders [73]. This model can contribute to elucidate how the consequences after early life stress can turn into issues that affect various domains in adolescence and adulthood, especially related to drug use behavior. A literature review study described that alcohol and other drug abuse could be adopted as a strategy to cope with early stress, resulting in consequences for various spheres of life of the individual, especially the labor aspects [74].

The present study provides ample evidence of the relationship and influence of early stress on drug dependence and suggests that crack users experience greater exposure to different types of early stress compared to alcohol users.

However, it is necessary to describe the limitations observed in this study. The size of the two samples, users of alcohol and crack, was relatively small. However, we minimized the sample bias by the fact that all individuals who sought treatment in the health unit during the scheduled collection period were invited to participate in the study. The problem of sample size had as a contributing factor the low demand for seeking care in outpatient health units for the treatment of drug-related disorders. Therefore, further studies with larger samples that include services with other levels of health care recommended.

The lack of information and control over possible confounding factors is pointed as a limitation, such as a gender. It was not possible to present the differences in early life stress between genders because the number of women in both samples was relatively small. Therefore, further analysis is necessary to adjust these confounding factors. Also, because this is a retrospective study, memory bias may be punctuated because prolonged drug use is a factor that may affect recall of childhood experience.

Despite these limitations, our results contribute to the scientific literature by expanding knowledge to understand the relationship between early life stress and the development of substance use disorders in adulthood, deepening the investigation of the variables present in this context. We emphasize the importance of these data for clinical practice since the trauma is often not recognized or even investigated in clinical settings. The disregard of traumatic experiences that generate early stress in the process of evaluation, planning, and implementation of treatment by professionals tends to contribute negatively to the development of a clinical practice capable of providing alternatives to drug users to cope with these traumas more effectively [40] [75].

In this sense, the results also contribute to legitimize the need for therapeutic approaches that can improve the physiological stress response, such as mindfulness-based interventions [76] [77] [78] have reported benefits for treating drug users.

\section{Conclusions}

The present study confirms the high prevalence of early life stress in drug users, especially among people diagnosed with crack dependence. The comparison be- 
tween the two groups made it possible to identify the influence and severity of early stress and to understand the seriousness of drug dependence among users, suggesting that crack users face greater exposure to different types of trauma in childhood and have a higher severity of drug dependence.

Our study contributes by providing evidence on the magnitude of the relationship between early stress and the influence of this experience on drug users. In the clinical setting, mental health nurses should be guided by the level of exposure of users to early stress and the type of drug used. Individually, we may suggest that the increased involvement of early stress may aggravate drug dependence in adulthood as a way to alleviate the long-term adverse effects of trauma exposure. Finally, we emphasize that the incorporation of early stress assessment in drug user care protocols can contribute to the comprehensive care offered, with the potential to improve the effectiveness of substance dependence treatment.

\section{Financing}

This work was funded by the University of Rio Verde [4.04.16.1.002].

\section{Conflicts of Interest}

The authors declare no conflicts of interest regarding the publication of this paper.

\section{References}

[1] United Nations Office on Drugs and Crime (UNODC) (2019) World Drug Report 2019. http://www.unodc.org/wdr2019 https://doi.org/10.18356/a4dd519a-en

[2] Fundação Oswaldo Cruz (FIOCRUZ) Instituto de Comunicação e Informação Científica e Tecnológica em Saúde. Rio de Janeiro (2017) III Levantamento Nacional sobre o uso de drogas pela população brasileira.

[3] Stoffel, C.M.M., Kessler, F.H.P., Pechansky, F., Lisia, Von D., Oliviera, M.F.M., Tatiana, H.L. and Santos, M.C. (2019) Crack Users and Violence. What Is the Relationship between Trauma, Antisocial Personality Disorder and Posttraumatic Stress Disorder? Addictive Behaviors, 98, Article ID: 106012. https://doi.org/10.1016/j.addbeh.2019.06.001

[4] Bellis, M.A., Hughes, K., Leckenby, N., Perkins, C. and Lowey, H. (2014) National Household Survey of Adverse Childhood Experiences and Their Relationship with Resilience to Health-Harming Behaviors in England. BMC Medicine, 12, Article No. 72. https://doi.org/10.1186/1741-7015-12-72

[5] Hughes, K., Bellis, M.A., Hardcastle, K.A., Sethi, D., Butchart, A., Mikton, C. and Dunne, M.P. (2017) The Effect of Multiple Adverse Childhood Experiences on Health: A Systematic Review and Meta-Analysis. The Lancet Public Health, 2, e356-e366. https://doi.org/10.1016/S2468-2667(17)30118-4

[6] Bernstein, D.P., Stein, J.A., Newcomb, M.D., Walker, E., Pogge, D., Ahluvalia, T. and Zule, W. (2003) Development and Validation of a Brief Screening Version of the Childhood Trauma Questionnaire. Child Abuse and Neglect, 27, 169-190. https://doi.org/10.1016/S0145-2134(02)00541-0 
[7] Menard, S., Covey, H.C. and Franzese, R.J. (2015) Adolescent Exposure to Violence and Adult Illicit Drug Use. Child Abuse and Neglect, 42, 30-39. https://doi.org/10.1016/j.chiabu.2015.01.006

[8] Huang, S., Trapido, E., Fleming, L., Arheart, K., Crandall, L., French, M. and Prado, G. (2011) The Long-Term Effects of Childhood Maltreatment Experiences on Subsequent Illicit Drug Use and Drug-Related Problems in Young Adulthood. Addictive Behaviors, 36, 95-102. https://doi.org/10.1016/j.addbeh.2010.09.001

[9] Skinner, M.L., Hong, S., Herrenkohl, T.I., Brown, E.C., Lee, J.O. and Jung, H. (2016) Longitudinal Effects of Early Childhood Maltreatment on Co-Occurring Substance Misuse and Mental Health Problems in Adulthood: The Role of Adolescent Alcohol Use and Depression. Journal of Studies on Alcohol and Drugs, 77, 464-472. https://doi.org/10.15288/jsad.2016.77.464

[10] LeTendre, M.L. and Reed, M.B. (2017) The Effect of Adverse Childhood Experience on Clinical Diagnosis of a Substance Use Disorder: Results of a Nationally Representative Study. Substance Use and Misuse, 52, 689-697.

https://doi.org/10.1080/10826084.2016.1253746

[11] Choi, N.G., DiNitto, D.M., Marti, C.N. and Choi, B.Y. (2017) Association of Adverse Childhood Experiences with Lifetime Mental and Substance Use Disorders among Men and Women Aged 50+ Years. International Psychogeriatrics, 29, 359-372. https://doi.org/10.1017/S1041610216001800

[12] United Nations Children's Fund (2014) Hidden in Plain Sight: A Statistical Analysis of Violence against Children. New York.

[13] World Health Organization (2014) Global Status Report on Violence Prevention 2014. World Health Organization, Geneva.

[14] Viola, T.W., Salum, G.A., Kluwe-Schiavon, B., Sanvicente-Vieira, B., Levandowski, M.L. and Grassi-Oliveira, R. (2016) The Influence of Geographical and Economic Factors in Estimates of Childhood Abuse and Neglect Using the Childhood Trauma Questionnaire: A Worldwide Meta-Regression Analysis. Child Abuse and Neglect, 51, 1-11. https://doi.org/10.1016/j.chiabu.2015.11.019

[15] International Society for the Prevention of Child Abuse and Neglect (2014) World Perspectives on Child Abuse. 11th Edition. https://www.ispcan.org/product/world-perspectives-on-child-abuse-13th-edition

[16] Enoch, M.A. (2011) The Role of Early Life Stress as a Predictor for Alcohol and Drug Dependence. Psychopharmacology, 214, 17-31. https://doi.org/10.1007/s00213-010-1916-6

[17] Enoch, M.A. (2012) The Influence of Gene-Environment Interactions on the Development of Alcoholism and Drug Dependence. Current Psychiatry Reports, 14, 150-158. https://doi.org/10.1007/s11920-011-0252-9

[18] Banducci, A.N., Hoffman, E., Lejuez, C.W. and Koenen, K.C. (2014) The Relationship between Child Abuse and Negative Outcomes among Substance Users: Psychopathology, Health, and Comorbidities. Addictive Behaviors, 39, 1522-1527. https://doi.org/10.1016/j.addbeh.2014.05.023

[19] Gimenez, L.B.H., Silveira, R.C.C.P., Silva, D.C.A. and Gherardi-Donato, E.C.S. (2016) Early Life Stress as Factor for Use of Psychoactive Substances: Integrative Review. Open Journal of Nursing, 6, 921-936. https://doi.org/10.4236/ojn.2016.611089

[20] Kepple, N.J. (2017) The Complex Nature of Parental Substance Use: Examining Past Year and Prior Use Behaviors as Correlates of Child Maltreatment Frequency. Substance Use and Misuse, 52, 811-821. https://doi.org/10.1080/10826084.2016.1253747 
[21] London, S., Quinn, K., Scheidell, J.D., Frueh, B.C. and Khan, M.R. (2017) Adverse Experiences in Childhood and Sexually Transmitted Infection Risk from Adolescence into Adulthood. Sexually Transmitted Diseases, 44, 524-532. https://doi.org/10.1097/OLQ.0000000000000640

[22] Hingray, C., Cohn, A., Martini, H., Donné, C., El-Hage, W., Schwan, R. and Paille, F. (2018) Impact of Trauma on Addiction and Psychopathology Profile in Alcohol-Dependent Women. European Journal of Trauma \& Dissociation, 2, 101-107. https://doi.org/10.1016/j.ejtd.2018.02.001

[23] Afifi, T.O., Henriksen, C.A., Asmundson, G.J.G. and Sareen, J. (2012) Childhood Maltreatment and Substance Use Disorders among Men and Women in a Nationally Representative Sample. Canadian Journal of Psychiatry, 57, 677-686. https://doi.org/10.1177/070674371205701105

[24] Scomparini, L.B., dos Santos, B., Rosenheck, R.A. and Scivoletto, S. (2013) Association of Child Maltreatment and Psychiatric Diagnosis in Brazilian Children and Adolescents. Clinics, 68, 1096-1102. https://doi.org/10.6061/clinics/2013(08)06

[25] Shin, S.H., Hong, H.G. and Hazen, A.L. (2010) Childhood Sexual Abuse and Adolescent Substance Use: A Latent Class Analysis. Drug and Alcohol Dependence, 109, 226-235. https://doi.org/10.1016/j.drugalcdep.2010.01.013

[26] Scheidell, J.D., Quinn, K., McGorray, S.P., Frueh, B.C., Beharie, N.N., Cottler, L.B. and Khan, M.R. (2018) Childhood Traumatic Experiences and the Association with Marijuana and Cocaine Use in Adolescence through Adulthood. Addiction, 113, 44-56. https://doi.org/10.1111/add.13921

[27] Tucci, A.M., Kerr-Corrêa, F., Lucia, M. and Souza-Formigoni, O. (2010) Childhood Trauma in Substance Use Disorder and Depression: An Analysis by Gender among a Brazilian Clinical Sample. Child Abuse \& Neglect, 34, 95-104. https://doi.org/10.1016/j.chiabu.2009.07.001

[28] Diehl, A., Clemente, J., Pillon, S.C., Santana, P.R.H., da Silva, C.J. and Mari, J.J. (2019) Early Childhood Maltreatment Experience and Later Sexual Behavior in Brazilian Adults Undergoing Treatment for Substance Dependence. Revista Brasileira de Psiquiatria, 41, 199-207. https://doi.org/10.1590/1516-4446-2017-0020

[29] Halpern, S.C., Scherer, J.N., Roglio, V., Faller, S., Sordi, A., Ornell, F., von Diemen, L., et al. (2017) Vulnerabilidades clínicas e sociais em usuários de crack de acordo com a situação de moradia: Um estudo multicêntrico em seis capitais Brasileiras. Cadernos de Saude Publica, 33, e00037517. https://doi.org/10.1590/0102-311x00037517

[30] Amorim, P. (2000) Mini-International Neuropsychiatric Interview (MINI): Validação de entrevista breve para diagnóstico de transtornos mentais. Revista Brasileira de Psiquiatria, 22, 106-115. https://doi.org/10.1590/S1516-44462000000300003

[31] Gossop, M., Dark, S., Griffiths, P., Hando, J., Powis, B., Hall, W. and Strang, J. (1995) The Severity of Dependence Scale (SDS): Psychometric Properties of the SDS in English and Australian Samples of Heroin, Cocaine and Amphetamine Users. Addiction, 90, 607-614. https://doi.org/10.1046/j.1360-0443.1995.9056072.x

[32] Gossop, M., Best, D., Marsden, J. and Strang, J. (1997) Test-Retest Reliability of the Severity of Dependence Scale. Addiction, 92, 353-354.

https://doi.org/10.1080/09652149738439

[33] Ferri, C.P., Marsden, J., De Araujo, M., Laranjeira, R.R. and Gossop, M. (2000) Validity and Reliability of the Severity of Dependence Scale (SDS) in a Brazilian Sample of Drug Users. Drug and Alcohol Review, 19, 451-455.

https://doi.org/10.1080/713659418 
[34] Kassim, S., Islam, S. and Croucher, R. (2010) Validity and Reliability of a Severity of Dependence Scale for khat (SDS-khat) Journal of Ethnopharmacology, 132, 570-577. https://doi.org/10.1016/j.jep.2010.09.009

[35] Castillo, I.I., Saiz, F.G., Rojas, Ó.L., Vázquez, M.Á.L. and Lerma, J.M.J. (2010) Estimation of Cutoff for the Severity of Dependence Scale (SDS) for Opiate Dependence by ROC Analysis. Actas Espanolas de Psiquiatria, 38, 270-277.

[36] Bernstein, D.P., Fink, L., Handelsman, L., Foote, J., Lovejoy, M., Wenzel, K. and Ruggiero, J. (1994) Initial Reliability and Validity of a New Retrospective Measure of Child Abuse and Neglect. American Journal of Psychiatry, 151, 1132-1136. https://doi.org/10.1176/ajp.151.8.1132

[37] Grassi-Oliveira, R., Stein, L.M. and Pezzi, J.C. (2006) Tradução e validação de conteúdo da versão em português do Childhood Trauma Questionnaire. Revista de Saude Publica, 40, 249-255. https://doi.org/10.1590/S0034-89102006000200010

[38] Grassi-Oliveira, R., Cogo-Moreira, H., Salum, G.A., Brietzke, E., Viola, T.W., Manfro, G.G. and Arteche, A.X. (2014) Childhood Trauma Questionnaire (CTQ) in Brazilian Samples of Different Age Groups: Findings from Confirmatory Factor Analysis. PLoS ONE, 9, e87118. https://doi.org/10.1371/journal.pone.0087118

[39] He, J., Zhong, X., Gao, Y., Xiong, G. and Yao, S. (2019) Psychometric Properties of the Chinese Version of the Childhood Trauma Questionnaire-Short Form (CTQ-SF) among Undergraduates and Depressive Patients. Child Abuse and Neglect, 91, 102-108. https://doi.org/10.1016/j.chiabu.2019.03.009

[40] Kongerslev, M.T., Bach, B., Rossi, G., Trauelsen, A.M., Ladegaard, N., Løkkegaard, S.S. and Bo, S. (2019) Psychometric Validation of the Childhood Trauma Questionnaire-Short Form (CTQ-SF) in a Danish Clinical Sample. Child Abuse and Neglect, 94, Article ID: 104026. https://doi.org/10.1016/j.chiabu.2019.104026

[41] Abdalla, R.R., Madruga, C.S., Ribeiro, M., Pinsky, I., Caetano, R. and Laranjeira, R. (2014) Prevalence of Cocaine Use in Brazil: Data from the II Brazilian National Alcohol and Drugs Survey (BNADS) Addictive Behaviors, 39, 297-301. https://doi.org/10.1016/j.addbeh.2013.10.019

[42] Butler, A.J., Rehm, J. and Fischer, B. (2017) Health Outcomes Associated with Crack-Cocaine Use: Systematic Review and Meta-Analyses. Drug and Alcohol Dependence, 1, 401-416. https://doi.org/10.1016/j.drugalcdep.2017.08.036

[43] Moreira, M.R., Fernandes, F.M.B., Ribeiro, J.M. and Franco Neto, T.L. (2015) A Review of Brazilian Scientific Output on Crack-Contributions to the Political Agenda. Ciencia e Saude Coletiva, 20, 1047-1062. https://doi.org/10.1590/1413-81232015204.03202014

[44] Gallassi, A.D., Nakano, E.Y., Wagner, G.A., de Oliveira Silva, M.N.R.M. and Fischer, B. (2016) Characteristics of Clients Using a Community-Based Drug Treatment Service ("CAPS-AD") in Brazil: An Exploratory Study. International Journal of Drug Policy, 31, 99-103. https://doi.org/10.1016/j.drugpo.2016.01.020

[45] Gifford, E. and Humphreys, K. (2007) The Psychological Science of Addiction. Addiction, 102, 352-361. https://doi.org/10.1111/j.1360-0443.2006.01706.x

[46] Pachado, M.P., Scherer, J.N., Guimarães, L.S.P., von Diemen, L., Pechansky, F., Kessler, F.H.P. and Almeida, R.M.M. (2018) Markers for Severity of Problems in Interpersonal Relationships of Crack Cocaine Users from a Brazilian Multicenter Study. Psychiatric Quarterly, 89, 923-936. https://doi.org/10.1007/s11126-018-9590-7

[47] Marchi, N.C., Scherer, J.N., Pachado, M.P., Guimarães, L.S., Siegmund, G., de Castro, M.N. and Kessler, F.H. (2017) Crack-Cocaine Users Have Less Family Cohe- 
sion than Alcohol Users. Revista Brasileira de Psiquiatria, 39, 346-351. https://doi.org/10.1590/1516-4446-2016-2091

[48] Sigurdsson, S.O., Ring, B.M., O’Reilly, K. and Silverman, K. (2012) Barriers to Employment among Unemployed Drug Users: Age Predicts Severity. American Journal of Drug and Alcohol Abuse, 38, 580-587. https://doi.org/10.3109/00952990.2011.643976

[49] Gossop, M., Manning, V. and Ridge, G. (2006) Concurrent Use of Alcohol and Cocaine: Differences in Patterns of Use and Problems among Users of Crack Cocaine and Cocaine Powder. Alcohol and Alcoholism, 41, 121-125. https://doi.org/10.1093/alcalc/agh260

[50] Oliveira, H.P., Gonçalves, P.D., Ometto, M., Santos, B., Malbergier, A., Amaral, R. and Cunha, P.J. (2018) The Route of Administration Exacerbates Prefrontal Functional Impairments in Crack Cocaine Users. Psychology of Addictive Behaviors, 32, 812-820. https://doi.org/10.1037/adb0000410

[51] Paim Kessler, F.H., Barbosa Terra, M., Faller, S., Ravy Stolf, A., Carolina Peuker, A., Benzano, D. and Pechansky, F. (2012) Crack Users Show High Rates of Antisocial Personality Disorder, Engagement in Illegal Activities and Other Psychosocial Problems. American Journal on Addictions, 21, 370-380. https://doi.org/10.1111/j.1521-0391.2012.00245.x

[52] Toledo, L., Góngora, A. and Bastos, F.I.P.M. (2017) On the Sidelines of Society: Crack Use, Deviation, Criminalization and Social Exclusion-A Narrative Review. Ciencia e Saude Coletiva, 22, 31-42. https://doi.org/10.1590/1413-81232017221.02852016

[53] Evren, C., Kural, S. and Cakmak, D. (2006) Clinical Correlates of Childhood Abuse and Neglect in Substance Dependents. Addictive Behaviors, 31, 475-485. https://doi.org/10.1016/j.addbeh.2005.05.030

[54] Schäfer, I., Langeland, W., Hissbach, J., Luedecke, C., Ohlmeier, M.D., Chodzinski, C. and Driessen, M. (2010) Childhood Trauma and Dissociation in Patients with Alcohol Dependence, Drug Dependence, or Both-A Multi-Center Study. Drug and Alcohol Dependence, 109, 84-89. https://doi.org/10.1016/j.drugalcdep.2009.12.012

[55] Andersen, S.L. (2019) Stress, Sensitive Periods, and Substance Abuse. Neurobiology of Stress, 10, Article ID: 100140. https://doi.org/10.1016/j.ynstr.2018.100140

[56] Werner, K.B., Sartor, C.E., McCutcheon, V.V., Grant, J.D., Nelson, E.C., Heath, A.C. and Bucholz, K.K. (2016) Association of Specific Traumatic Experiences with Alcohol Initiation and Transitions to Problem Use in European American and African American Women. Alcoholism: Clinical and Experimental Research, 40, 2401-2408. https://doi.org/10.1111/acer.13220

[57] Fuller-Thomson, E., Roane, J.L. and Brennenstuhl, S. (2016) Three Types of Adverse Childhood Experiences, and Alcohol and Drug Dependence among Adults: An Investigation Using Population-Based Data. Substance Use and Misuse, 51, 1451-1461. https://doi.org/10.1080/10826084.2016.1181089

[58] Konstenius, M., Leifman, A., van Emmerik-van Oortmerssen, K., van de Glind, G., Franck, J., Moggi, F. and Van Den Brink, W. (2017) Childhood Trauma Exposure in Substance Use Disorder Patients with and without ADHD. Addictive Behaviors, 65, 118-124. https://doi.org/10.1016/j.addbeh.2016.10.016

[59] Tonmyr, L. and Shields, M. (2017) Childhood Sexual Abuse and Substance Abuse: A Gender Paradox? Child Abuse and Neglect, 63, 284-294. https://doi.org/10.1016/j.chiabu.2016.11.004

[60] Khosravani, V., Samimi Ardestani, S.M., Sharifi Bastan, F., Mohammadzadeh, A. 
and Amirinezhad, A. (2019) Childhood Maltreatment, Cognitive Emotion Regulation Strategies, and Alcohol Craving and Dependence in Alcohol-Dependent Males: Direct and Indirect Pathways. Child Abuse \& Neglect, 98, Article ID: 104197. https://doi.org/10.1016/j.chiabu.2019.104197

[61] Sordi, A.O., Hauck, S., Laitano, H., Halpern, S., Schuch, S., Kessler, F. and Pechansky, F. (2015) Childhood Trauma and Resilience: Vulnerabilities to Develop Crack/Cocaine Dependence. Journal of Alcoholism and Drug Dependence, 3, 6. https://doi.org/10.4172/2329-6488.1000227

[62] Prangnell, A., Fairgrieve, C., Nosova, E., DeBeck, K., Milloy, M.J. and Hayashi, K. (2019) High Prevalence of Self-Reported Exposure to Adulterated Drugs among People Who Experienced an Opioid Overdose in Canada: A Cohort Study. Substance Use and Misuse, 54, 980-985. https://doi.org/10.1080/10826084.2018.1555257

[63] Tractenberg, S.G., Viola, T.W., Rosa, C.S.O., Donati, J.M., Francke, I.D.A., Pezzi, J.C. and Grassi-Oliveira, R. (2012) Exposição a trauma e transtorno de estresse pós-traumático em usuárias de crack. Jornal Brasileiro de Psiquiatria, 61, 206-213. https://doi.org/10.1590/S0047-20852012000400003

[64] Narvaez, J.C.M., Magalhães, P.V.S., Trindade, E.K., Vieira, D.C., Kauer-Sant'Anna, M., Gama, C.S. and Kapczinski, F. (2012) Childhood Trauma, Impulsivity, and Executive Functioning in Crack Cocaine Users. Comprehensive Psychiatry, 53, 238-244. https://doi.org/10.1016/j.comppsych.2011.04.058

[65] Halpern, S.C., Schuch, F.B., Scherer, J.N., Sordi, A.O., Pachado, M., Dalbosco, C. and Von Diemen, L. (2018) Child Maltreatment and Illicit Substance Abuse: A Systematic Review and Meta-Analysis of Longitudinal Studies. Child Abuse Review, 27, 344-360. https://doi.org/10.1002/car.2534

[66] Sanvicente-Vieira, B., Rovaris, D.L., Ornell, F., Sordi, A., Rothmann, L.M., Niederauer, J.P.O. and Grassi-Oliveira, R. (2019) Sex-Based Differences in Multidimensional Clinical Assessments of Early-Abstinence Crack Cocaine Users. PLoS ONE, 14, e0218334. https://doi.org/10.1371/journal.pone.0218334

[67] Schwandt, M.L., Heilig, M., Hommer, D.W., George, D.T. and Ramchandani, V.A. (2013) Childhood Trauma Exposure and Alcohol Dependence Severity in Adulthood: Mediation by Emotional Abuse Severity and Neuroticism. Alcoholism: Clinical and Experimental Research, 37, 984-992. https://doi.org/10.1111/acer.12053

[68] Saddichha, S., Fliers, J.M., Frankish, J., Somers, J., Schuetz, C.G. and Krausz, M.R. (2014) Homeless and Incarcerated: An Epidemiological Study from Canada. International Journal of Social Psychiatry, 60, 795-800. https://doi.org/10.1177/0020764014522776

[69] Mandavia, A., Robinson, G.G.N., Bradley, B., Ressler, K.J. and Powers, A. (2016) Exposure to Childhood Abuse and Later Substance Use: Indirect Effects of Emotion Dysregulation and Exposure to Trauma. Journal of Traumatic Stress, 29, 422-429. https://doi.org/10.1002/jts.22131

[70] Kessler, F. and Pechansky, F. (2008) Uma visão psiquiátrica sobre o fenômeno do crack na atualidade. Revista de Psiquiatria Do Rio Grande Do Sul, 30, 96-98. https://doi.org/10.1590/S0101-81082008000300003

[71] Cicchetti, D. and Rogosch, F.A. (2018) A Developmental Psychopathology Perspective on Substance Use: Illustrations from the Research on Child Maltreatment. In: Fitzgerald, H.E. and Puttler, L.I., Eds., Alcohol Use Disorders. A Developmental Science Approach to Etiology, Oxford University Press, Oxford, 17-29. https://doi.org/10.1093/oso/9780190676001.003.0002 
[72] Cicchetti, D. and Handley, E.D. (2019) Child Maltreatment and the Development of Substance Use and Disorder. Neurobiology of Stress, 10, Article ID: 100144. https://doi.org/10.1016/j.ynstr.2018.100144

[73] Oshri, A., Rogosch, F.A., Burnette, M.L. and Cicchetti, D. (2011) Developmental Pathways to Adolescent Cannabis Abuse and Dependence: Child Maltreatment, Emerging Personality, and Internalizing versus Externalizing Psychopathology. Psychology of Addictive Behaviors, 25, 634-644. https://doi.org/10.1037/a0023151

[74] Fernandes, M.N.F. and Gherardi-Donato, E.C.S. (2017) Is It Workplace Stress a Trigger for Alcohol and Drug Abuse? Open Journal of Nursing, 7, 435-448. https://doi.org/10.4236/ojn.2017.73034

[75] Zeanah, C.H. and Humphreys, K.L. (2018) Child Abuse and Neglect. Journal of the American Academy of Child and Adolescent Psychiatry, 57, 637-644. https://doi.org/10.1016/j.jaac.2018.06.007

[76] Cavicchioli, M., Movalli, M. and Maffei, C. (2018) The Clinical Efficacy of Mindfulness-Based Treatments for Alcohol and Drugs Use Disorders: A Meta-Analytic Review of Randomized and Nonrandomized Controlled Trials. European Addiction Research, 24, 137-162. https://doi.org/10.1159/000490762

[77] Vadivale, A.M. and Sathiyaseelan, A. (2019) Mindfulness-Based Relapse Prevention-A Meta-Analysis. Cogent Psychology, 6, 1-13. https://doi.org/10.1080/23311908.2019.1567090

[78] Esper, L.H. and Gherardi-Donato, E.C.S. (2019) Mindfulness-Based Interventions for Women Victims of Interpersonal Violence: A Systematic Review. Archives of Psychiatric Nursing, 33, 120-130. https://doi.org/10.1016/j.apnu.2018.09.003 


\section{Appendix}

\section{Suicidal Behavior and Early Life Stress in Users of Psychoactive} Substances

Coordinator: Prof. Msc. Elton Brás Camargo Júnior

Patient's code:

Interviewer:

Interview date:

\section{P-Sociodemographic Profile}

P1-Gender (1) male; (2) female)

P2-Date of birth:

(Age:

P3-What color do you consider yourself?

1) Black; 5) Indigenous

2) White 6) Other

3) Yellow

4) Mestizo/pardo

P4-What is your marital status?

1) Married 4) Divorced

2) Domestic partnership 5) Separated

3) Widower 6) single

P5-Education

1) Illiterate 3) Incomplete/complete secondary school

2) Incomplete/complete primary school 4) Incomplete/complete college

Note: Specify last school year:

P6-What is your main current employment situation?

1) Full time (TI) (35+h/week),

2) Part time $(<35 \mathrm{~h} /$ week $)$

3) Unemployed and actively looking for a "temporary layoff"

4) Outside the labor market-does not work and does not actively seek work

5) Casual work (irregular work and no fixed schedule)

6) Retired 


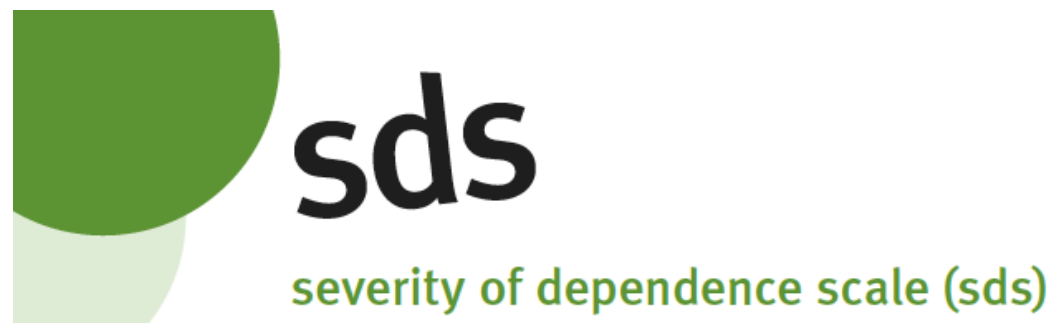

ncpic national cannabis prevention and information centre

Over the last 3 months:

1. Did you ever think your use of cannabis was out of control?

Never or almost never

Sometimes

Often

Always or nearly always

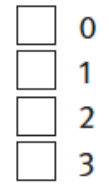

2. Did the prospect of missing a smoke make you very anxious or worried?

Never or almost never

Sometimes

Often

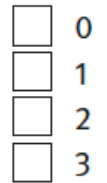

Always or nearly always

3. Did you worry about your use of cannabis?

Not at all

A little

Quite a lot

A great deal

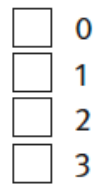

4. Did you wish you could stop?

Never or almost never

Sometimes

Often

Always or nearly always

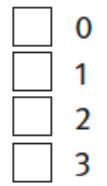

5. How difficult would you find it to stop or go without?

Not difficult

Quite difficult

Very difficult

Impossible

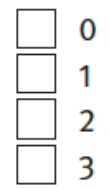

sds score / 15

(NB) Please note there are two cut-off scores: one for adults; SDS score of 3 and the other for adolescents; SDS score of 4.

Swift, W., Copeland, J. \& Hall, W. (1998). Choosing a diagnostic cut-off for cannabis dependence. Addiction 93, 1681-1692.

Martin, G., Copeland, J., Gates, P., \& Gilmore, S. (2006). The Severity of Dependence Scale (SDS) in an adolescent population of cannabis users: Reliability, validity and diagnostic cut-off. Drug and Alcohol Dependence 83, 90-93. 


\title{
M.I.N.I.
}

\section{MINI INTERNATIONAL NEUROPSYCHIATRIC INTERVIEW}

\author{
English Version 7.0.2
}

For

\section{DSM-5}

\section{(C) Copyright 1992-2016 Sheehan DV}

All rights reserved. No part of this document may be reproduced or transmitted in any form, or by any means, electronic or mechanical, including photocopying, or by any information storage or retrieval system, without permission in writing from Dr. Sheehan. Individual researchers, clinicians and students working in nonprofit or publicly owned settings (including universities, nonprofit hospitals, and government institutions) may make paper copies of a M.I.N.I. instrument for their personal clinical and research use, but not for institutional use, or for any financial profit or gain. Any use involving financial gain requires a license agreement from the copyright holder and payment of a per use license fee.

\section{DISCLAIMER}

Our aim is to assist in the assessment and tracking of patients with greater efficiency and accuracy. Before action is taken on any data collected and processed by this program, it should be reviewed and interpreted by a licensed clinician.

This program is not designed or intended to be used in the place of a full medical and psychiatric evaluation by a qualified licensed physician - psychiatrist. It is intended only as a tool to facilitate accurate data collection and processing of symptoms elicited by trained personnel. It is not a diagnostic test.

M.I.N.I. 7.0.2 (August 8,2016$)(8 / 8 / 16)$ 